\title{
Gas Metal Arc Root Welding of Pearlitic Rails Using Magnetic Arc Deflection
}

\author{
Leonhard Weingrill ${ }^{1, *}$, Martin Schwald ${ }^{1}$, David Frühstück $^{1}$, Clemens Faustmann $^{1}$ and Norbert Enzinger ${ }^{1}$ \\ ${ }^{1}$ IMAT Institute of Material Science, Joining and Forming, Graz University of Technology, 8010 Graz, Austria
}

\begin{abstract}
Magnetic arc deflection was applied to improve gas metal arc root welds on R260 pearlitic rail steel foot samples. During laboratory welding trials parameter optimization was carried out which comprised the welding current, voltage and speed, layer sequence, filler wire diameter, and the external magnetic field. Results were evaluated by visual inspection, and the lateral and diagonal penetration in cross-sections, as well as the microstructure and the hardness in the HAZ. Additionally, the influence of the external magnetic field on the process was studied using a high-speed camera. Overall best results were finally obtained in high welding current spray arc mode (380-400A) with the $1,6 \mathrm{~mm}$ solid wire and at high welding speed $(65 \mathrm{~cm} / \mathrm{min})$ and two pass per layer sequence, in combination with maximum $30 \mathrm{mT}$ magnetic flux density and increased welding voltage (30$31 \mathrm{~V}$ ) for longer arc. A continuously well-formed root with sufficient lateral penetration was achieved and a smooth transition from base metal to weld metal at the lower edges could be achieved. Inside base metal HAZ the microstructure was fully pearlitic and no soft zone occurred. Furthermore, the size of the HAZ was in comparison to aluminothermic weld reduced by more than $75 \%$ in comparison to an AT rail weld.
\end{abstract}

\section{Introduction}

Continuously welded rail strings are common today for multiple reasons. However, the welds can still represent weak spots of the track. This is related to softening of the base material inside the heat affected zone (HAZ). Furthermore, increased risk of complete failures is encountered statistically reproducible more often due to welding induced flaws.[1]-[4].

Aluminothermic (AT) welding is still the preferred process for joining rails in the track, accounting for about 3 Mio welds per year worldwide [5]. Amongst this process's advantages are the very little demand in equipment and infrastructure and thus little costs, as well as the very good gap bridging tolerances. Some disadvantages of AT-welds also exist: Reduced toughness of the weld because of the casting microstructure. Additionally there is an unavoidable hardness drop at the outer limits of the heat affected zone (HAZ) [6]-[8] as a result of the process' high heat input. This regions shows reduced resistance to wear and rolling contact fatigue. Furthermore, being a fully manual process, the quality of the joint depends on the welder's skills and personal condition.

Gas metal arc (GMA) welding would be presumably a very good alternative process to overcome the mentioned disadvantages of AT-welding. First of all, the welding parameters and filler material can be adapted layer by layer. Thus the microstructure of the weld and thus its mechanical properties can be locally adjusted. E.g., whereas high strength and ductility for improved fatigue strength at the root at the rail foot are required, high hardness for increased wear resistance is necessary at the rail head. Furthermore, GMA welding can be very well automatized. As a result, the welds do not depend on the manual skills of the welder. Thus the quality of the welds can be more easily monitored.

However, automated GMA welding for joining rails in track would mean a completely new approach to the sector. Due to high safety requirements extensive characterization and testing of weld joints is required. For admittance of a new process all relevant standards must be fulfilled.

\subsection{Approach to solution}

Throughout preliminary studies the root of GMA welded rails has been identified as a critical aspect of a GMA welded rail. It critically determines the fatigue strength of the joint. However, it is also the most difficult part of the weld due to the very restricted accessibility at the foot.

The objective of this work was to fundamentally investigate a new approach's potential to improve the root of GMA welded pearlitic rails. The novelty lies in the application of an external magnetic field to cause a purposeful disturbance of the electromagnetic forces of the weld arc, droplets and weld pool. As a result the arc and weld pool are laterally deflected. Thus the penetration and the geometry of weld root can be improved. Besides improved welding results this 
approach should bear two practical advantages when compared to methods of mechanically deflecting the weld wire dip:

First, the necessary magnetic unit is principally very simple and robust. Maintenance efforts for mechanical parts can be reduced. Thus practicability for in track welding is improved and operation costs reduced.

Second, through controlling the current in the magnetic coils in magnitude and direction, also the external magnetic field can be altered. Thus, the welding process can be adjusted to one's needs. E.g. the direction of deflection can be inversed for each pass individually.

\section{Experiments}

The experiments consisted of numerous welding trials under laboratory conditions and evaluation through visual inspection, macrographs to measure the penetration and metallography in cross sections of the weld.

\subsection{Setup and equipment for welding trials}

The used setup in is schematically shown in Fig. 1. A Fronius TPS 4000 CMT® power source (not depicted in Fig. 1) and corresponding water cooled narrow gap welding torch were used. The torch was mounted in neutral position on a stationary stand together with slightly sidewise tilted magnetic yoke. The legs of the magnetic yoke were aligned parallel to the welding direction. The tips of the legs were positioned symmetrically and closest possible to the tip of the filler wire.

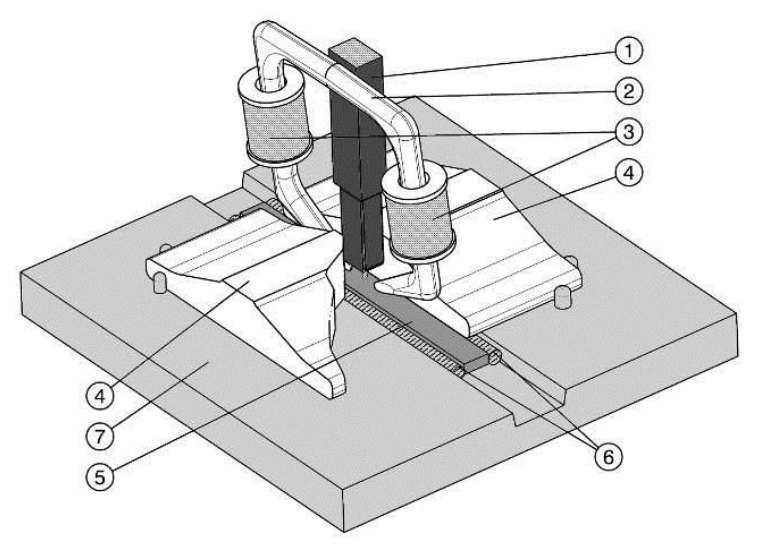

Fig. 1. Schematic depiction of experimental setup. $1 \ldots$ welding torch $2 \ldots$ magnetic yoke $3 \ldots$ coils $4 \ldots$ rail foot samples $5 \ldots$ steel strip for weld pool support $6 \ldots$ ceramic tube lateral backing 7 ... clamping and support plate.

The magnetic field was introduced with the help of two coils of 500 windings, which were clamped to the upper part of each of the two legs of the yoke. Electric current to the windings was supplied by a separate laboratory power unit (not depicted in Fig. 1) with adjustable DC voltage and current.

In order to guarantee for reproducible positioning weld samples were clamped on a dedicated support plate with alignment pins on each side knee levers. In order to fit the weld pool backing a clearance was milled into the support plate. Furthermore, along both sides of the weld gap at the bottom edges ceramic tubes were pressed into the remaining gap between steel strip, samples and support plate in order to back the penetrating weld metal and shape a smooth transition collar from base metal to weld metal. The entire setup was mounted on a table which was actuated by an automated linear axis and thus controlled the welding speed. By moving the sample instead of the weld torch it was possible to keep the HF-camera focused on the welding process throughout the entire length of the weld. M21 (82\% Argon, 18\% CO2) shielding gas was used for all experiments at $121 / \mathrm{min}$.

\subsection{Weld samples and used materials}

The used samples were made of R260 rail steel of $60 \mathrm{E} 1$ geometry. The web and head of the rails have been cut off and the remaining foot part then cut into $5 \mathrm{~cm}$ long pieces. A $16 \mathrm{~mm}$ wide steel strip of standard structural steel was placed at the bottom side of the $16 \mathrm{~mm}$ wide weld gap to support the weld pool. Its top surface was evenly levelled to the bottom surface of the rail foot samples, so that the edges of strip and samples touched in one line one each side. These strips optimum thickness was found to be $6 \mathrm{~mm}$. It was fixed to the samples with three manual TIG spots on the bottom surface on each side of the weld gap. s. Fig. 2. This was done to facilitate the otherwise difficult manipulation of heavy samples and access to the weld root layers. The weld flanks were vertical straight in as sawed condition with no specific preparation.

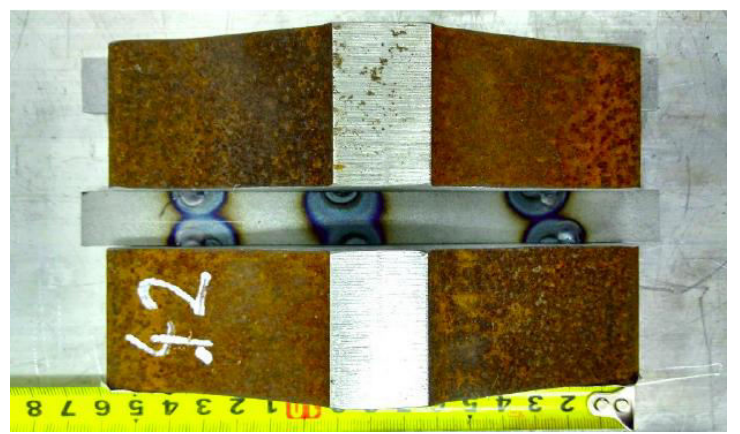

Fig. 2. Rail samples used for welding experiments.

Table 1. Nominal chemical composition of the used R260 rail steel according to

\begin{tabular}{|c|c|c|c|c|c|}
\hline \multicolumn{6}{|c|}{ Main alloying elements weight $-\%$} \\
\hline $\mathrm{C}$ & $\mathrm{Si}$ & $\mathrm{Mn}$ & $\mathrm{P}$ max. & $\mathrm{S}$ max. & $\mathrm{Cr}$ \\
\hline $0,62-$ & $0,15-$ & $0,70-$ & 0,025 & 0,025 & $\leq 0,15$ \\
0,80 & 0,58 & 1,20 & & & \\
\hline
\end{tabular}

For all experiments a standard G3Sil wire from voestalpine Boehler Welding was used as a filler material. 


\subsection{Experimental procedures}

Welding parameter optimization was carried out in multiple welding trials. These were structured into three separate series. This was necessary to optimize the heat input per unit of length (HI) and the magnetic deflection separately.

First, for identification of the optimum $\mathrm{HI}$ the welding current, $I_{W}$, and the welding speed $V_{w}$ were systematically altered in multiple combinations, covering all weldable areas which allowed for a stable process. Therefore, also 3 different filler wire diameters $\mathrm{d}_{\mathrm{F}}$ were used. The tried parameter ranges are shown in Table 2. Welds in the first series were single pass welds with single-sided deflection only. The evaluation was done by visual inspection and macrographs of at least one cross section per weld.

Table 2. Welding parameter variation ranges during heat input optimization.

\begin{tabular}{|l|c|c|}
\hline $\mathrm{d}_{\mathrm{F}} / \mathrm{mm}$ & $\mathrm{I}_{\mathrm{W}} / \mathrm{A}$ & $\mathrm{V}_{\mathrm{W}} / \mathrm{cm} \cdot \mathrm{min}^{-1}$ \\
\hline 1,0 & $200-270$ & $19,8-33$ \\
\hline 1,2 & $285-360$ & 33 \\
\hline 1,6 & $202-400$ & $19,8-69$ \\
\hline
\end{tabular}

Based on the found parameters for optimum HI investigations were then focused on the magnetic deflection in the second series. Parameter optimization herein comprised the alteration of the magnetic flux density via the coil current $I_{C}$ from $1 \mathrm{~A}$ to $3 \mathrm{~A}$. Furthermore the influence of increased welding voltage was investigated. It was therefore varied from the standard characteristic within a range of $+/-20 \%$.

The welded samples of this series were evaluated based on measurement of the lateral and diagonal penetration $\left(\mathrm{a}_{\mathrm{i}}\right.$ and $\left.\mathrm{c}_{\mathrm{i}}\right)$ at the root in three cross sections at $1 / 4,1 / 2$ and $3 / 4$ of the length of the weld and in longitudinal direction of the rail, s. Fig. 3 .

In addition, a high-speed camera was used in this series to study the influence of varied parameters on the behavior of the weld arc, droplet detachment and the weld pool.

For what concerns evaluation of the high speed camera images, although the welding process was stable some agitation of the weld arc and irregularities of the direction of motion the droplet was always present. Therefore it was difficult to measure the angle of arc deflection and droplets deflections directly. Thus the angle of deflection of the molten wire tip and vertical filler wire was used as a reference instead.

The third and optimization series served to adjust the HI of the second pass. Furthermore samples were preheated up to $300^{\circ} \mathrm{C}$.

All findings were then combined into a comprehensive parameter set which was used to produce representative prototype welds in third experiment series.

Standard metallography methods were applied for cross section preparation. Adler etchant was used for macrographs. Nital $3 \%$ was used for microstructure investigations.
Hardness measurements were done with the help of and automated machine and the method was HV10.

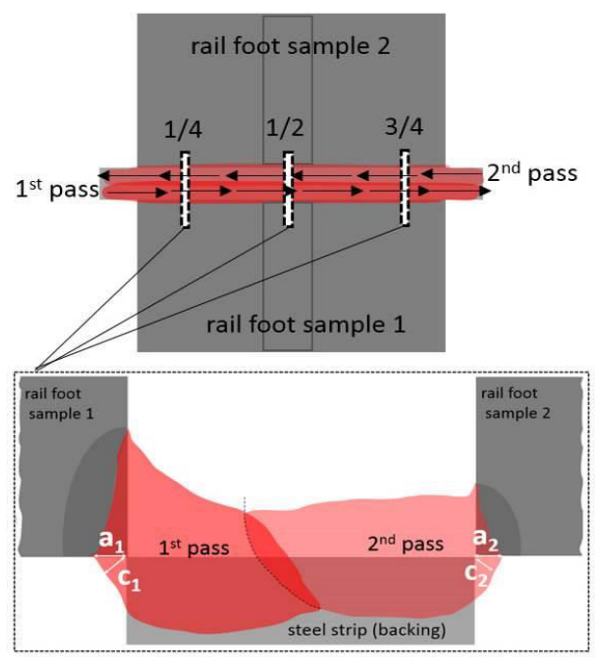

Fig. 3: Schematic of weld sequence and longitudinal cross sections for evaluation of lateral $a_{i}$ and diagonal $c_{i}$ penetration at the root.

\section{Results}

\subsection{Welding parameter optimization}

First of all, for what concerns the diameter of the filler wire the best results were obtain by using the largest $\mathrm{d}_{\mathrm{F}}$ of $1.6 \mathrm{~mm}$ wire. The influence of the $\mathrm{d}_{\mathrm{f}}$ can be derived from Fig. 3.
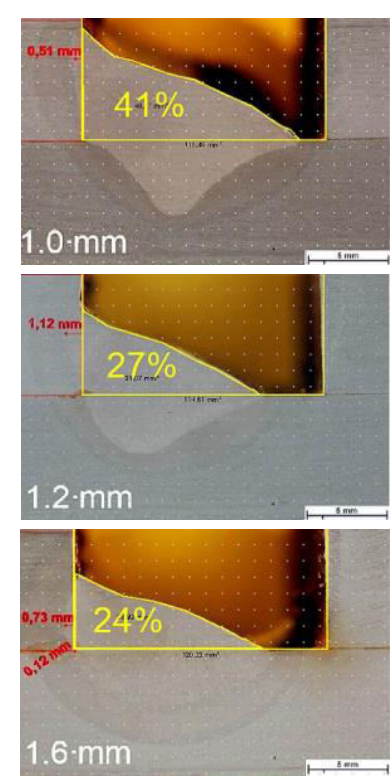

Fig. 4. Comparison of penetration and degree of gap filling for varied filler wire diameter but same $I_{W}$ and $V_{W}$

By comparing the shapes of the weld pool it can be derived that it was flatter and wider for larger $d_{F}$. Although it penetrates vertically deeper for small $d_{F}$, this maximum penetration is of narrow shape and located too little to the side of the weld gap. Therefore $\mathrm{c}_{\mathrm{i}}=0$ and no root is formed. This fact can also be derived from the overall relative position of the weld 
bead inside the weld gap. The weld bead literally sits deep and more to the side for larger $d_{F}$. This can be derived from the indicated degree of weld gap filling It decreases with increasing $d_{F}$ and thus the maximum lateral penetration's relative position is lowered and therefore closer to the intended location close to the lateral lower edge of the root.

Best results were in general obtained with highest $\mathrm{I}_{\mathrm{W}}$ and in spray arc mode. $\mathrm{I}_{\mathrm{W}}$ should be maximized in order to maximize also the overall penetration. Spray arc was beneficial because droplets can be better deflected.

However, best penetration results did not depend on $I_{w}$ alone. The penetration was found highest if the ratio of $I_{W}$ and the deposition rate was highest possible. This was realized through also a high welding speed. $\mathrm{V}_{\mathrm{W}}$. It was found that if the weld gap is filled too fast because of the high deposition rate as a result of high $\mathrm{I}_{\mathrm{W}}$ the weld pool cannot penetrate laterally at the lowest section of the weld root.

Contrary to that, through a relatively lower deposition rate through increase of $\mathrm{V}_{\mathrm{W}}$ the weld gap is not filled slower. Thus the arc and weld pool can penetrate low and on the side of the weld gap for longer and thus $\mathrm{a}_{\mathrm{i}}$ and $\mathrm{c}_{\mathrm{i}}$ are increased. This means, both $\mathrm{I}_{\mathrm{W}}$ and $\mathrm{V}_{\mathrm{W}}$ must be increased within stable process limits and the $1,6 \mathrm{~mm}$ wire used in order to obtain the best results. This aspect can be explained by the for GMAW inherent direct relation of $I_{w}$ and the deposition rate because of automated wire feed, but was not anticipated to play a major role for this application.

An almost linear relation of the coil current $\mathrm{I}_{\mathrm{C}}$ and the tilt angle of the molten wire dip could be found, s.Fig. 4. It led to the rather simple conclusion that the higher the magnetic field the better the lateral deflection of weld arc and droplets and thus the lateral and diagonal penetration. With regards to penetration this principally means the higher the coil current and thus the stronger the magnetic field the better were the welding results.

However, if $\mathrm{I}_{\mathrm{C}}$ was increased to $>3 \mathrm{~A}$ the yoke adhered to the weld sample which caused a magnetic shortcut. As a result the deflection of arc and droplets was less because the magnetic field deviated through the weld samples and was therefore lessened in the area of the weld.

For what concerns the welding voltage $U_{W}$ it was found that a relative increase from the standard welding characteristic is beneficial for the deflection. First it increases the $\mathrm{HI}$ und thus the overall penetration. Second, increasing $U_{W}$ increases the length of the weld arc, s. Fig. 6 Error! Reference source not found.. The in this way increased trajectory of the droplets also increases the length of interaction of the external magnetic field with the weld arc and droplets in transfer. Thus, the arc can be better deflected and the droplets can travel further to the side which improves the penetration.

However, this alteration of $U_{W}$ had a clear upper limit. If $\mathrm{U}_{\mathrm{W}}$ was increased by more than $12 \%$ away from the standard characteristic the arc started to bounce outside from the weld gap. As a result the weld process became unstable. Arc interruptions and droplet expulsion resulted in weld flaws of different types, such as increased spatter and in some sections high amount of pores indicated disturbance of the gas flow. Even worse, if $\mathrm{U}_{\mathrm{W}}$ was increased up to $20 \%$ secondary arc ignited in between the wire guide and the nozzle of the torch which led to damages.

(a)

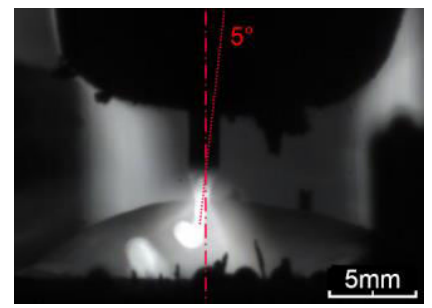

(b)

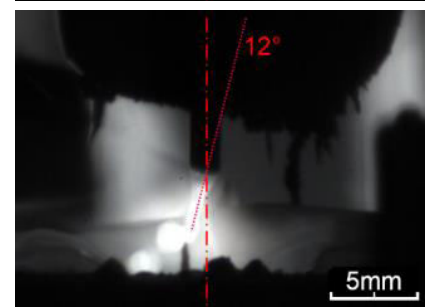

(c)

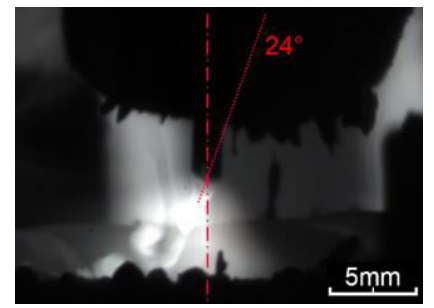

Fig. 5. Weld arc and droplet transfer behavior for constant welding parameters $\mathrm{Iw}, \mathrm{V}_{\mathrm{W}}$ and $\mathrm{U}_{\mathrm{W}}$ but varying strength of external magnetic field via $\mathrm{I}_{\mathrm{C}}(\mathrm{a}) \ldots \mathrm{I}_{\mathrm{C}}=1 \mathrm{~A} \quad(5 \mathrm{mT})$ (b)... $\mathrm{I}_{\mathrm{C}}=2 \mathrm{~A}(10 \mathrm{mT})(\mathrm{c}) \ldots \mathrm{I}_{\mathrm{C}}=3 \mathrm{~A}(20 \mathrm{mT})$.

(a)

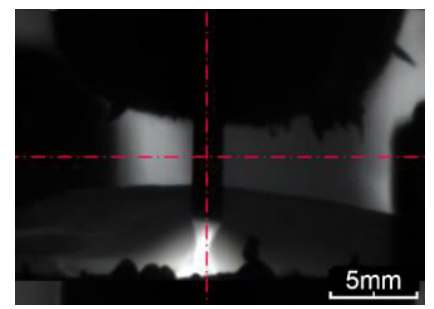

(b)

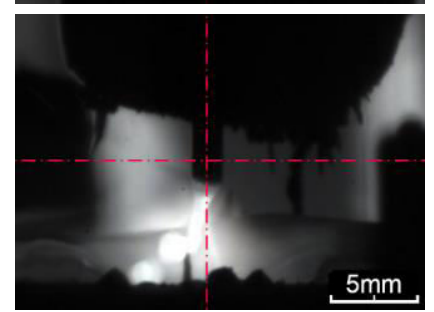

(c)

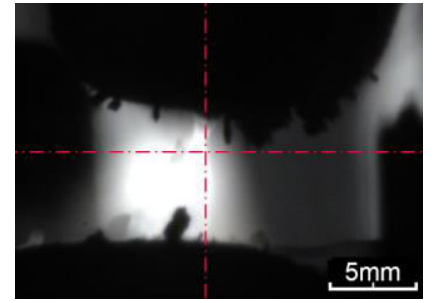

Fig. 6. Weld process behavior under constant $I_{W}, V_{W}$ and $I_{C}$ but varying $\mathrm{U}_{\mathrm{W}}$. (a) ...0\% (b)... $+10 \%$ (c)... $+20 \%$. 
For completeness of results presentation it is mentioned here as well that the welding in pulsed $I_{w}$ mode under influence of the external magnetic field caused an overall very unstable process. Thus no further investigations on beneficial influence of pulsed $\mathrm{I}_{\mathrm{W}}$ were carried out in this work.

The proposed optimum welding parameter set for the first and the second pass are given in Table 3.

Table 3. Optimum welding parameters.

\begin{tabular}{|l|c|c|c|c|}
\hline pass & $\begin{array}{c}\mathrm{I}_{\mathrm{w}} \\
/ \mathrm{A}\end{array}$ & $\begin{array}{c}\mathrm{U}_{\mathrm{W}} \\
/ \mathrm{V}\end{array}$ & $\begin{array}{c}\mathrm{V}_{\mathrm{W}} \\
/{ }_{\text {cm.min }}{ }^{-1}\end{array}$ & $\begin{array}{c}\text { coil current } \mathrm{I}_{\mathrm{C}} \\
/ \mathrm{A}\end{array}$ \\
\hline $\mathbf{1}^{\text {st }}$ & 400 & 31,1 & 64,5 & 2,9 \\
\hline $\mathbf{2}^{\text {nd }}$ & 380 & 30,7 & 64,5 & 2,9 \\
\hline
\end{tabular}

\subsection{Final optimization weld root}

Fig.10 (a) and (b) show the lateral bottom overview of the optimized root weld from both sides. With exception for sidewise run-in and run-out zones a continuously well-established root is formed on both sides. Cross sections of this same weld are depicted in Fig. 7. The corresponding measured lateral $a_{i}$ and diagonal $c_{i}$ penetration is shown in Fig. 8. The penetration and the geometry of the root collar are not constant throughout the weld. Maximum measured lateral and diagonal penetration are $3.5 \mathrm{~mm}$ respectively $2.2 \mathrm{~mm}$ for the $1^{\text {st }}$ pass and $1.8 \mathrm{~mm}$ respectively $1.4 \mathrm{~mm}$ for the $2^{\text {nd }}$ pass. Thus although sufficient for both side, root formation is not equal. The $1^{\text {st }}$ pass overall showed a better result.

If both these aspects are taken as the main evaluation criterion - wherein a smoother transition from the rail bottom surface to the backing strip and more penetration are considered beneficial for better fatigue strength - the following statements are drawn:

Overall the root is sufficiently formed with the help of the parameter optimization and magnetic deflection. The root of the $1^{\text {st }}$ pass is better formed. Although both sides of the root improve throughout the weld the root of $1^{\text {st }}$ pass is also improves better. These findings are drawn back to the better accessibility of the heat of the weld arc and pool when the weld gap is still fully open during the 1st pass.

(a)

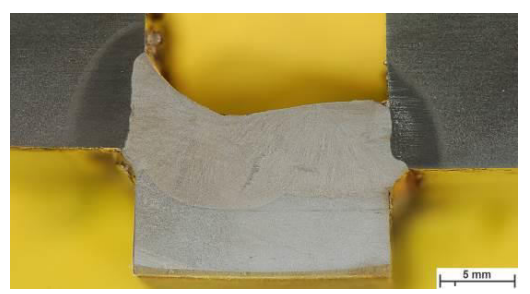

(b)

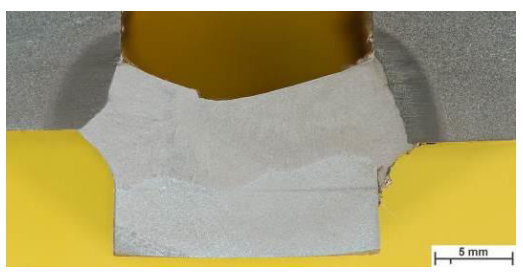

(c)

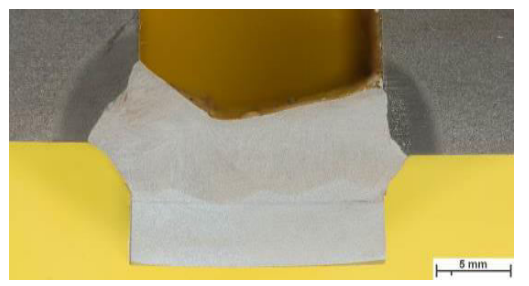

Fig. 7. Root geometry after parameter optimization at (a)... $1 / 4$ (b) .. $1 / 2$ (c) .. $3 / 4$ of weld.

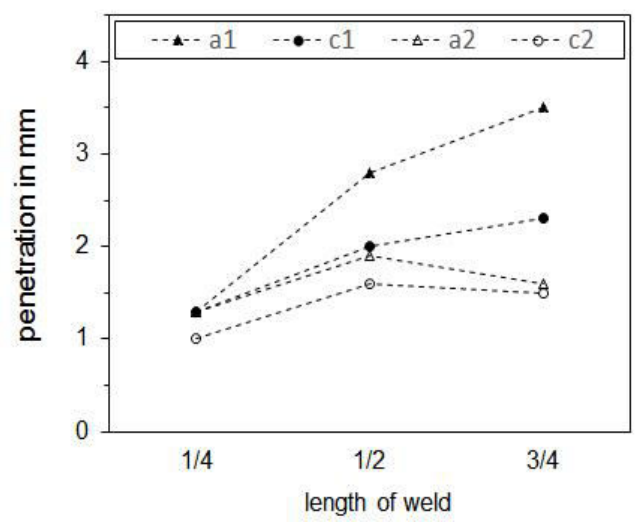

Fig. 8. Lateral and diagonal penetration in the evaluated cross sections for $1^{\text {st }}$ and $2^{\text {nd }}$ pass.

(a)

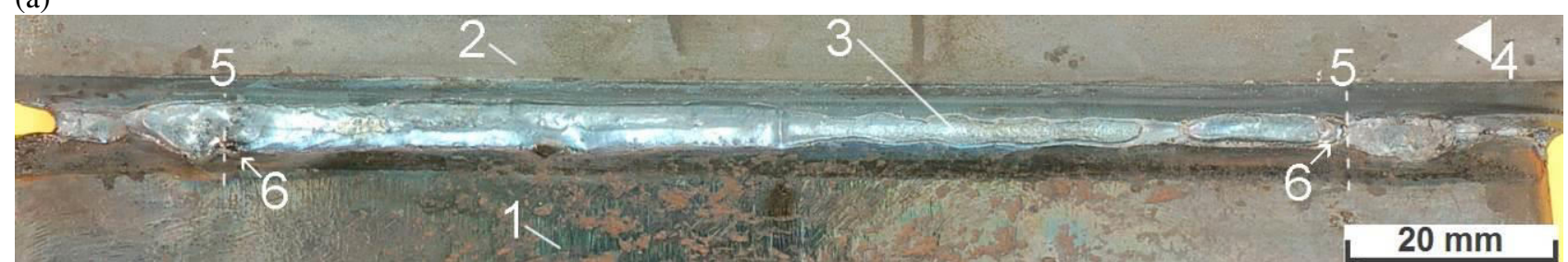

(b)

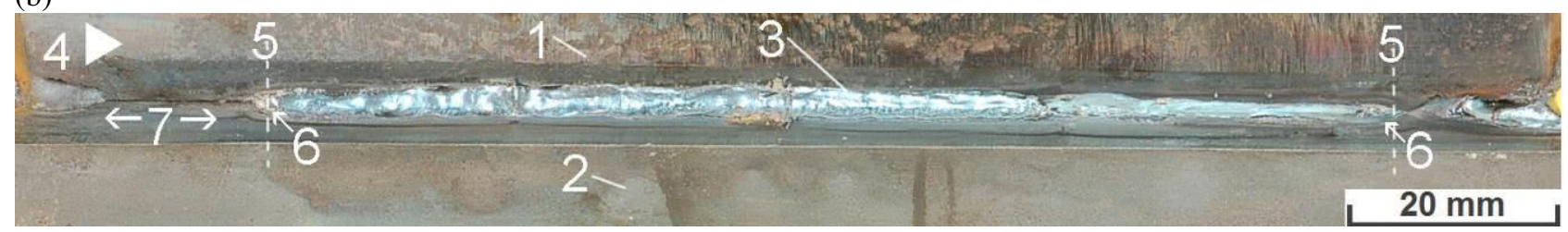

Fig. 9. Bottom view of optimized weld root (a) $\ldots 1^{\text {st }}$ pass (b) $\ldots 2^{\text {nd }}$ pass. $1 \ldots$ rail foot $2 \ldots$ weld pool backing inlay $3 \ldots$ weld root $4 \ldots$ welding direction $5 \ldots$ sidewise run-in/ run-out zones $6 \ldots$ TIG fixation weld spots $7 \ldots$ no root formation. 
In order to depict the beneficial influence of the magnetic deflection in Fig. 9 a cross section taken from the middle of a single pass weld with same Iw and $\mathrm{V}_{\mathrm{W}}$ as for the 1st pass but without magnetic deflection is shown, to depict the benefit of the magnetic deflection. It can be seen that the weld sits in the center of the weld gap. No lateral bonding nor any penetration is achieved.

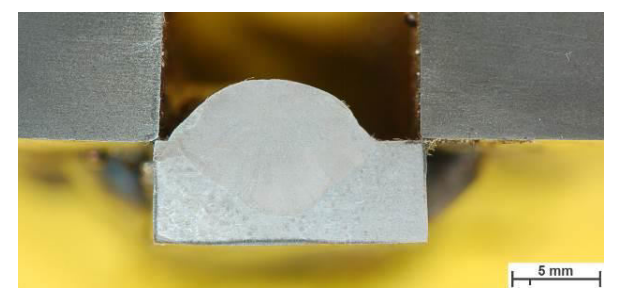

Fig. 10. Root geometry of an exemplary reference single pass without magnetic arc deflection

Microstructures at different locations of the HAZ of the cross section in (c) presented cross section of the with weld root layer Fig. 11. It can be derived that the heat affected zone (HAZ) of the rail steel consist entirely of Pearlite, s Fig. 11 (a), (b), (d) and (e). Beside the fully pearlitic matrix dispersed dark spots - in higher resolution there elongated shape was identified - inside the HAZ are Mn-sulfides inclusions, marked with $\mathrm{S}$ in Fig. 11 (a) and (e). These are results from the production of the steel, as no significant change of their shape and distribution was found in between HAZ and base metal (BM) is found. For resolutions up to $1000 \mathrm{x}$ besides these two constituents no other phases were found in the HAZ. The weld metal (WM) consist of acicular ferrite, s. Fig. 11 (f), this is what was to be the expected microstructure of the used G3Si filler wire. Within a narrow band of about $50 \mathrm{~m}$ width along the fusion line, s. Fig. 11 (f) plate-shaped pre-eutectoid ferrite (marked with F) is found at the former austenite grain boundaries. Its formation is understood as a result of decreased carbon content caused by the high difference in carbon content between the rail steel and filler wire. Although fully pearlitic, it can be derived from Fig. 11 (a) that the optical appearance of the HAZ varies. This is an indication of the changing Pearlite morphology, which for pearlitic microstructure is defined by the colony and nodule size. Inside the HAZ close from the transition from BM these are smaller in size and thus the much morphology is refined, s. Fig.10 (b). Further on, the morphology is gradually coarsening towards the WM. However inside the coarse grain zone it is still finer then in the BM, compare Fig. 11 (b) top left corner and HAZ in Fig. 11 (c). The variation of morphology of the pearlitic microstructure is off course a result of the variation of different thermal cycles from welding.
The hardness distribution along the cross section is shown below the overview image in Fig. 11. The hardness in the HAZ is constantly higher than the one of the base BM. The hardness increases from the BM towards the WM to over $450 \mathrm{HV} 10$. The hardness in the weld metal is generally on a lower level, which is a result of the used filler wire.

\section{Discussion}

The fact that weldability of GMAW for pearlitic rails is very limited was approved in this work. Furthermore, as this work was done under laboratory conditions findings may for now only be considered as one fundamental step towards an implementation of GMAW for on the track welding of rails. However, it has to be pointed out that limited does not mean entirely not given. Thus it was in the same way very clearly shown in this work that by applying the correct and sufficient precautions sound GMA welding of the root layer of pearlitic rails is possible.

A very important question should be raised here: Is the geometry of the root collar and the achievable penetration good enough to deliver sufficient fatigue strength to the joint in the track. We would state the answer as follows: for what concerns the bond respectively the connections quality the here presented results are sufficient to withstand the loading requirement in the track. However, with regards to the applicability for in the track welding where ease of use and high gap bridging tolerances at $100 \%$ reproducibility are essential the obtained maximum lateral penetration especially for the $2^{\text {nd }}$ pass is believed not enough. A minimum penetration of $3 \mathrm{~mm}$ is believed necessary on both sides at a gap bridging tolerance of $+/-10 \mathrm{~mm}$.

Still, advantages of the new process over ATwelding can be as well pointed out based on the findings. The hardness and size of the HAZ of the GMAW approach and of an exemplary state of the art AT weld are compared to each other in Fig. 12. It can be derived that the size of the HAZ is reduced by about $75 \%$. Furthermore, there are no drops in hardness at the transition from BM to HAZ. In contrast to AT-welds the hardness in the HAZ of the GMA welded rail is constantly above the one of the BM. If projected to the rail head, these two aspects in combination with the optimization possibilities of GMA the new approach is believed to contain high potential to overcome the problematic of reduced wear resistance of rail welds, especially for the latest developed hypereutectoid steel grades of hardness above $400 \mathrm{HBW}$. 


\section{Overview}

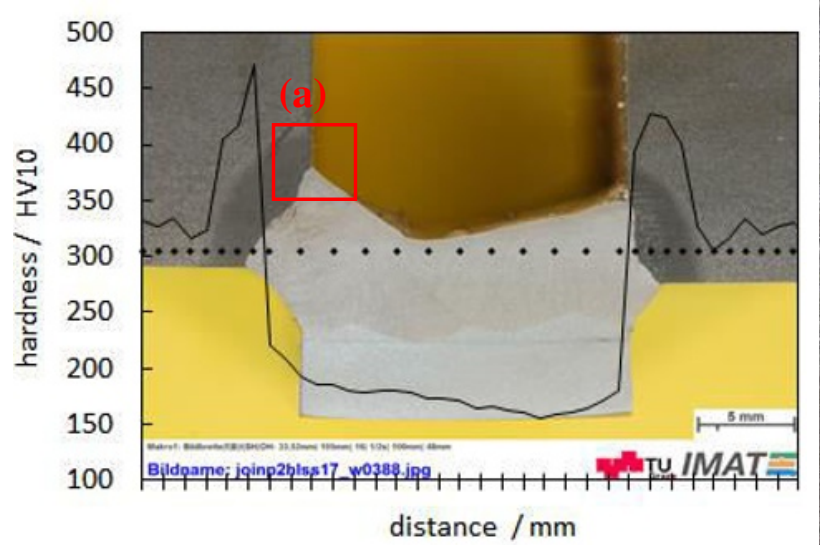

(b)

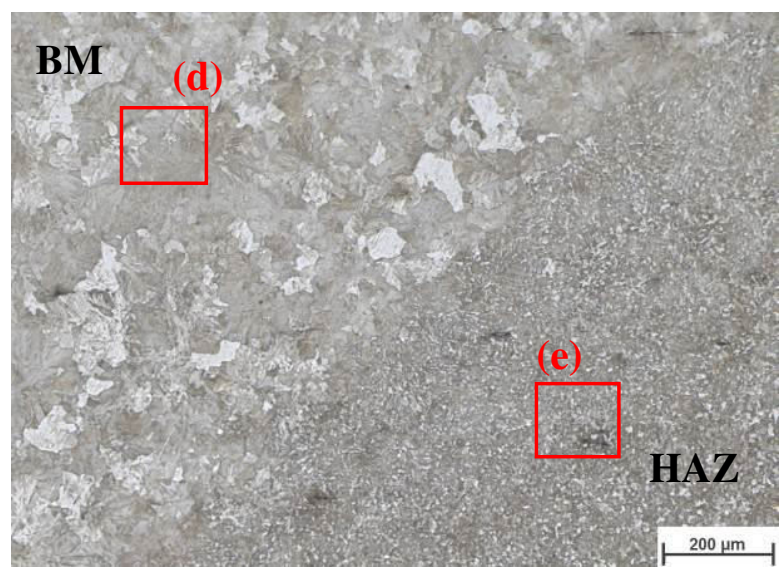

(d)

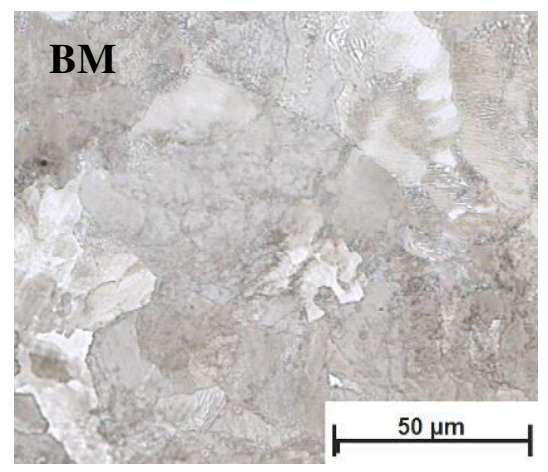

(e)

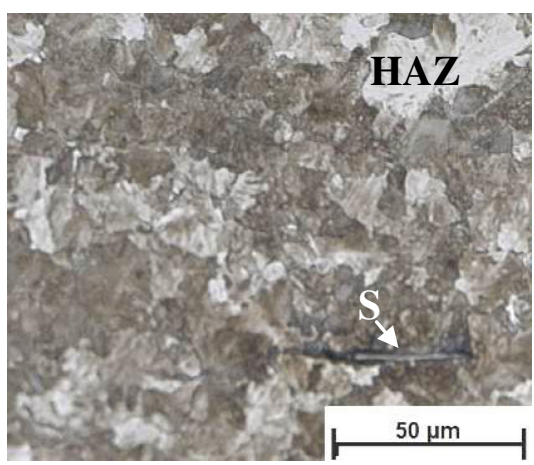

(a)

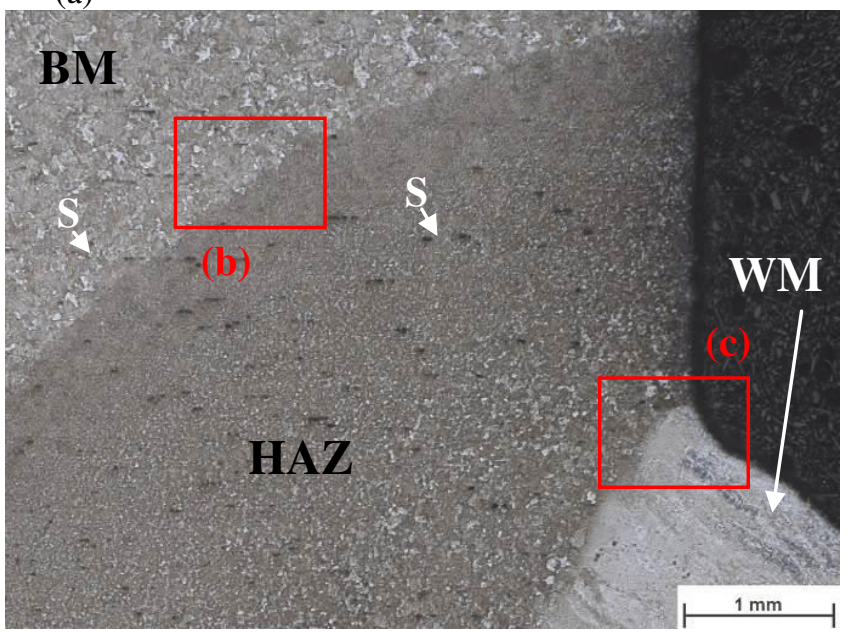

(c)

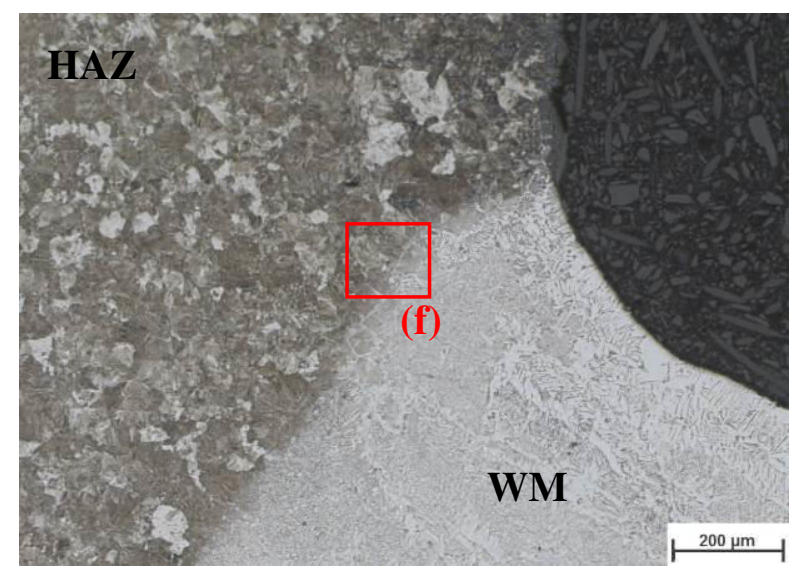

(f)

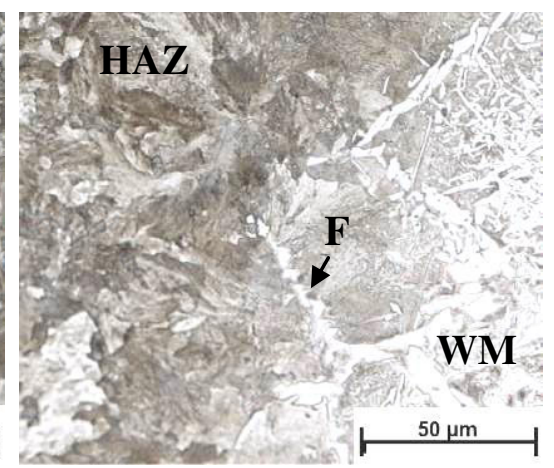

Fig. 11. Microstructure at the different areas of the weld.

\section{Conclusions}

GMA root welding experiment of pearlitic rails under laboratory conditions can give very promising results if welding is carried out following these aspects:

- two-pas-per-layer sequence, with for each pass and section-wise well optimized parameters

- lateral weld arc deflection by an external magnetic field parallel to the welding direction and with magnetic flux density at the weld of at least $30 \mathrm{mT}$, the higher the magnetic field the better the deflection, however high magnetic field can cause mechanical problems to the yoke

- the welding parameters are set to:

1. the highest possible ratio of the welding current $\mathrm{I}_{\mathrm{W}}$ and the deposition rate (via high welding speed $\mathrm{V}_{\mathrm{W}}$ )

2. spray arc mode for $1.6 \mathrm{~mm}$ filler wire

- a relative increase of the welding voltage $U_{\mathrm{W}}$ of up to $12 \%$ 
By that a smooth transition collar of the root and maximum lateral penetration of $3.5 \mathrm{~mm}$ could be obtained.

If preheated to $300^{\circ} \mathrm{C}$ the microstructure in the entire HAZ is fully pearlitic. The hardness inside the $\mathrm{HAZ}$ is above the hardness of the $\mathrm{BM}$ as a result of the refined morphology of the Pearlite. Compared to a state-of-the-art AT-weld no hardness sacks are formed and the width of the HAZ is reduced by $75 \%$ to about to $25 \mathrm{~mm}$.

However, it also has to be stated that the penetration at the root was found to be not constant over the full length of the weld. Lateral run- in and run-out zones with partial no root formation at the $2^{\text {nd }}$ pass were found. Therefore theses lateral zone of the weld still need special emphasis.

Found results at the current state leave a lot of further optimization necessary. With regards to suitability for in the track welding all the remaining layers of the rails entire cross section would additionally still need to be optimized. From that background, the biggest challenge is believed to be the transition from the here investigated laboratory condition to in the track welding. This means that the approach is believed to have great potential for rail welding it's however not yet suitable for in track application.

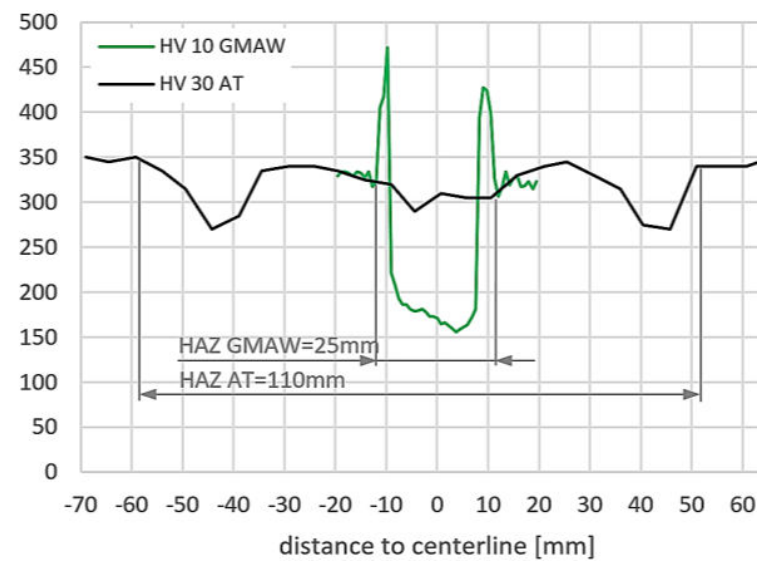

Fig. 12. Hardness distribution in longitudinal cross section. Comparison of hardness and size of HAZ for two welds of same rail but different process. Green... GMAW with optimized two-pass-per-layer sequence and magnetic deflection from this work. Black... exemplary state of the art AT-weld.

\section{Outlook}

The fundamental studies of this work have pointed out a strong potential of GMAW for pearlitic rails. However these further investigations are believed essential to bring the process closer to an in track applicability:

- improved design of magnetic unit (magnetic flux and mechanical fixation)

- even out higher penetration of $1^{\text {st }}$ and $2^{\text {nd }}$ pass by improved balancing of penetration
- improve results at run-in and run-out area via further optimization of welding parameters and setup

- Welding of remaining layers and fatigue strength testing of the welded rails

Future topics of interest we would like to follow up based on the made findings are:

- Magnetically actuated to both sides oscillating weld arc

- Alternative filler wire for matching pearlitic weld metal

The K-Project Network of Excellence for Metal JOINing is fostered in the frame of COMET - Competence Centers for Excellent Technologies by BMWFW, BMVIT, FFG, Land Oberösterreich, Land Steiermark, Land Tirol and SFG. The programme COMET is handled by FFG.

\section{References}

1. European Commission, "Fourth report on monitoring development of the rail market," pp. 143, 2014.

2. A. Skyttebol, B. L. Josefson, and J. W. Ringsberg, "Fatigue crack growth in a welded rail under the influence of residual stresses," Eng. Fract. Mech., vol. 72, pp. 271-285, 2005.

3. A. Ekberg and B. Paulsson, "Concluding technical report - Innotrack." International Union of Railways (UIC), p. 288, 2010.

4. S. Romano, D. Manenti, S. Beretta, and U. Zerbst, "Semi-probabilistic method for residual lifetime of aluminothermic welded rails with foot cracks," Theor. Appl. Fract. Mech., vol. 85, pp. 398-411, 2016.

5. Competence Center Welding (CCW), "voestalpine Schienen GmbH, Leoben/Donawitz AUSTRIA." Leoben/Donawitz AUSTRIA, 2015.

6. P. Micenko and H. Li, "Double Dip Hardness Profiles in Rail Weld Heat-affected Zone Literature and Research Review Report," Brisbane, Australia, 2013.

7. P. J. Mutton and E. F. Alvarez, "Failure modes in aluminothermic rail welds under high axle load conditions," Eng. Fail. Anal., vol. 11, pp. 151-166, 2004.

8. J. Keichel and R. Gehrmann, "Neues ThermitSchweißverfahren SkV-Elite," Elektro Thermit $\mathrm{GmbH} \& \mathrm{Co} K G$ Halle Germany, EIEisenbahingenieur, pp. 50-53, Sep-2008.

9. "Railway applications - Track - Rail - Part 1: Vignole railway rails $46 \mathrm{~kg} / \mathrm{m}$ and above." Austrian/European Standard OENORM EN 136741,2011 . 